\title{
Dietary soya protein concentrate enriched with isoflavones reduced fatty liver, increased hepatic fatty acid oxidation and decreased the hepatic mRNA level of VLDL receptor in obese Zucker rats
}

\author{
Oddrun A. Gudbrandsen ${ }^{1 *}$, Hege Wergedahl ${ }^{1}$, Sverre Mørk $^{2}$, Bjørn Liaset $^{3}$, Marit Espe ${ }^{3}$ and Rolf K. Berge ${ }^{1}$ \\ ${ }^{1}$ Institute of Medicine, Section of Medical Biochemistry, University of Bergen, Haukeland University Hospital, N-5021 Bergen, \\ Norway \\ ${ }^{2}$ Gade Institute, Department of Pathology, University of Bergen, Haukeland University Hospital, N-5021 Bergen, Norway \\ ${ }^{3}$ National Institute of Nutrition and Seafood Research, Box 2029 Nordnes, N-5817 Bergen, Norway
}

(Received 9 December 2005 - Revised 29 March 2006 - Accepted 19 April 2006)

\begin{abstract}
Casein-based diets containing a low (LDI) or high (HDI) dose of soya protein concentrate enriched with isoflavones were fed to obese Zucker rats for 6 weeks. HDI feeding, but not LDI feeding, reduced the fatty liver and decreased the plasma levels of alanine transaminase and aspartate transaminase. This was accompanied by increased activities of mitochondrial and peroxisomal $\beta$-oxidation, acetyl-CoA carboxylase, fatty acid synthase and glycerol-3-phosphate acyltransferase in liver and increased triacylglycerol level in plasma. The decreased fatty liver and the increased plasma triacylglycerol level appeared not to be caused by an increased secretion of VLDL, as HDI decreased the hepatic mRNA levels of apo B and arylacetamide deacetylase. However, the gene expression of VLDL receptor was markedly decreased in liver, but unchanged in epididymal white adipose tissue and skeletal muscle of rats fed HDI, indicating that the liver may be the key organ for the reduced clearance of triacylglycerol-rich lipoproteins from plasma after HDI feeding. The $n-3 / n-6,20: 4 n-6 / 18: 2 n-6$ and $(20: 5 n-3+22: 6 n-3) / 18: 3 n-3$ ratios were increased in liver triacylglycerol by HDI. The phospholipids in liver of rats fed HDI contained a low level of $20: 4 n-6$ and a high level of $20: 5 n-3$, favouring the production of anti-inflammatory eicosanoids. When obese Zucker rats were fed soya protein, this also resulted in reduced fatty liver, possibly through reduced clearance of VLDL by the liver. We conclude that the isoflavone-enriched soya concentrate as well as soya protein may be promising dietary supplements for treatment of non-alcoholic fatty liver.
\end{abstract}

Steatosis: $\beta$-Oxidation: Lipogenesis

Non-alcoholic fatty liver disease affects $10-24 \%$ of the general global population, but the prevalence increases significantly, to more than $50 \%$, for obese people (Silverman et al. 1990; Angulo \& Lindor, 2002). It has been estimated that $5-10 \%$ of obese individuals are obese due to insufficient leptin production, while the remaining $90-95 \%$ are believed to be leptin resistant (Cohen \& Friedman, 2004). The genetically obese Zucker fa/fa rats have a null mutation of the leptin receptor gene and have been extensively studied as a model for obesity in man. These rats also have high plasma triacylglycerol levels and abnormally high synthesis of triacylglycerol in liver, combined with a low rate of fatty acid oxidation in liver (Bray, 1977; Triscari et al. 1982), leading to development of fatty liver at a young age (Krief \& Bazin, 1991). The obese Zucker fa/fa rats may therefore be useful as an animal model for a deeper understanding of biochemical changes that occur during the development and treatment of fatty liver.

There is no widely accepted therapy for fatty liver, but lifestyle modifications with weight reduction are frequently recommended (McClain et al. 2004), and one approach has been changes in the diet with special focus on dietary fats. Increasing evidence suggests that not only dietary lipids and fatty acids, but also proteins and amino acids in the diet can affect lipid metabolism. It has been known for some years that dietary soya products lower the serum total cholesterol and LDL cholesterol in man (Anderson et al. 1995) and animals (Sirtori et al. 1993), and may have a cardioprotective effect. The components and mechanisms responsible for the hypocholesterolaemic effect of soya products have not been clarified. It has been suggested that the amino acid composition of soya protein, with low ratios of methionine/glycine and lysine/arginine, contribute to its cholesterol-lowering effect (Kritchevsky et al. 1982; Morita et al. 1997), but several reports have shown that this might be due to components other than amino acids, e.g. isoflavones (primarily genistein and daidzein) that are associated with the soya protein (Huff et al. 1977; Potter, 1995; Balmir et al. 1996; Madani et al. 1998; Peluso et al. 2000; Fukui et al. 2002; Ali et al. 2004).

Abbreviations: AADA, arylacetamide deacetylase; CPT, carnitine palmitoyltransferase; FAT/CD36, fatty acid translocase; HDI, diet containing a high dose of soya protein concentrate enriched with isoflavones; LDI, diet containing a low dose of soya protein concentrate enriched with isoflavones; LPL, lipoprotein lipase; SCD-1, stearoyl-CoA desaturase; WAT, white adipose tissue.

* Corresponding author: Dr Oddrun A. Gudbrandsen, fax +47 55973115, email nkjgu@uib.no 
We have previously demonstrated that when obese Zucker rats were fed a diet containing soya protein, which contains isoflavones, a lowering of the plasma cholesterol level and of the lipid content in liver resulted (Wergedahl et al. 2004). Similar results have also been reported by Peluso et al. (2000) after dietary treatment with the isoflavone-enriched fraction of isolated soya protein to obese Zucker rats. In the present study we performed two experiments: first, we wanted to study whether a dietary soya concentrate enriched in isoflavones could reduce the fatty liver in obese Zucker rats, and to elucidate the mechanism behind this event; second, obese Zucker rats were fed intact soya protein to see whether this would reduce the fatty liver via the same mechanisms as the isoflavone-enriched soya concentrate.

\section{Materials and methods}

\section{Animals and diets}

Two experiments were performed. In the first experiment, male obese Zucker rats Crl:(ZUC)/FaBR (fa/fa) from Charles River Laboratory. (Sulzfeld, Germany), weighing 80-135 g, were divided into three experimental groups of six rats each with comparable mean body weight. The rats were housed individually all through the feeding experiment in a room maintained at a $12 \mathrm{~h}$ light-dark cycle and a constant temperature of $20 \pm 3^{\circ} \mathrm{C}$ and relative humidity of $65 \pm 15 \%$. The rats were acclimatised under these conditions before the start of the experiment. The rats were fed diets consisting of $20 \%$ (by weight) protein from casein sodium salt from bovine milk (C-8654; Sigma-Aldrich Norway AS, Oslo, Norway) or casein-added fermented soyabeans with high contents of genistein and daidzein. Two doses of isoflavones were used. The diet with a low amount of soya protein concentrate enriched with isoflavone (LDI) contained $21.4 \%$ casein and $0.7 \%$ fermented soya proteins, providing $0.40 \mathrm{~g}$ genistein $/ \mathrm{kg}$ diet and $0.45 \mathrm{~g}$ daidzein $/ \mathrm{kg}$ diet. The diet with a high-dose of soya protein concentrate enriched with isoflavone (HDI) contained $18.4 \%$ casein and $6.7 \%$ fermented soya proteins, providing $4.00 \mathrm{~g}$ genistein $/ \mathrm{kg}$ diet and $4.50 \mathrm{~g}$ daidzein $/ \mathrm{kg}$ diet. Choline hydrogentartrate $(0.2 \%$; Merck, Darmstadt, Germany) was added to all diets. The rats were fed these diets for 6 weeks. All rats had free access to tap water and feed. Based on daily observations of the rats, it seemed that all experimental diets were well tolerated. Table 1 gives an overview of the experimental diets.

In the second experiment, male obese Zucker rats Crl:(ZUC)/FaBR (fa/fa) from Charles River Laboratory, weighing 80-135 g, were fed diets similar to the diets in the first experiment, except that they contained $20 \%$ protein from either soya protein or casein, and the rats were fed these diets for 3 weeks. Table 1 gives an overview of the experimental diets (for more details on the diets and experimental conditions, see Wergedahl et al. 2004).

At the end of the feeding period, under non-fasting conditions, the rats were anaesthetised with a 1:1 mixture of Hypnorm ${ }^{\text {TM }}$ $(0.315 \mathrm{mg} / \mathrm{ml}$ fentanyl citrate and $10 \mathrm{mg} / \mathrm{ml}$ fluanisone; Janssen Pharmaceutica, Beerse, Belgium) and Dormicum ${ }^{\circledR}(5 \mathrm{mg} / \mathrm{ml}$ midazolam; F. Hoffmann-La Roche AG, Basel, Switzerland) injected subcutaneously. Blood was drawn directly from the heart using a syringe containing heparin. The liver was immediately removed, weighed and divided into two parts, which were
Table 1. Composition of the experimental diets $(\mathrm{g} / \mathrm{kg}$ diet)*

\begin{tabular}{|c|c|c|c|c|c|}
\hline & \multicolumn{3}{|c|}{ Experiment 1} & \multicolumn{2}{|c|}{ Experiment 2} \\
\hline & Caseint & LDI & HDI§ & Caseint & Soyall \\
\hline Casein sodium salt & 218 & 214 & 184 & 218 & - \\
\hline $\begin{array}{l}\text { Soya protein } \\
\text { concentrate }\end{array}$ & - & 7 & 67 & - & - \\
\hline Soya protein & - & - & - & - & 227 \\
\hline Soya oilq & 100 & 100 & 100 & 100 & 100 \\
\hline Sucrose & 110 & 110 & 110 & 110 & 110 \\
\hline Vitamins $^{\star *}$ & 10 & 10 & 10 & 10 & 10 \\
\hline Minerals†† & 30 & 30 & 30 & 30 & 30 \\
\hline Cellulose & 20 & 20 & 20 & 20 & 20 \\
\hline Dextrin & 512 & 509 & 479 & 491 & 484 \\
\hline
\end{tabular}

* The diets were isoenergetic and isonitrogenous, and contained $200 \mathrm{~g}$ crude protein $/ \mathrm{kg}$ diet.

† Casein (g/kg diet): fat (98), ash (31). The casein protein contained $91.9 \%$ crude protein.

$\ddagger$ LDI, diet containing a low dose of soya protein concentrate enriched with isoflavones ( $\mathrm{g} / \mathrm{kg}$ diet): fat (99), ash (31), genistein (0.40), daidzein (0.45). The soya protein concentrate contained $45.4 \%$ crude protein

$\S \mathrm{HDI}$, diet containing a high dose of soya protein concentrate enriched with isoflavones ( $\mathrm{g} / \mathrm{kg}$ diet): fat $(99)$, ash (30), genistein (4.00), daidzein (4.50). The soya protein concentrate contained $45.4 \%$ crude protein.

\| Diet containing soya protein ( $\mathrm{g} / \mathrm{kg}$ diet): fat (101), ash (54). The soya protein contained $88.0 \%$ crude protein. The diets in Experiment 2 had $2 \% \mathrm{NaCl}$ added.

ๆ Fatty acid composition of the soya oil (mean of two measurements, deviation less than $3 \%$, shown as $\mathrm{g} / 100 \mathrm{~g}$ fat): $18: 2 n-6(55.9), 18: 1 n-9(21.4), 16: 0(11.4)$, $18: 3 n-3(5 \cdot 8), 18: 0(3 \cdot 3), 18: 1 n-7(1 \cdot 6)$

** AIN-93VX (Dyets Inc., Bethlehem, PA, USA).

††AIN-93G-MX (Dyets Inc.).

immediately chilled on ice or frozen in liquid N. Plasma, liver, epididymal white adipose tissue (WAT) and skeletal muscle from the thigh were stored at $-80^{\circ}$ until analysis. The protocol was approved by the Norwegian State Board of Biological Experiments with Living Animals.

\section{Fatty acid composition}

Lipids were extracted from liver and plasma samples using a mixture of chloroform and methanol (Bligh \& Dyer, 1959). The lipid classes in liver were separated by TLC on silica gel plates $(0.25 \mathrm{~mm}$ Silica gel 60 ; Merck) developed in hexane-diethyl ether-acetic acid (80:20:1, by vol.; Mangold, 1969). The spots were identified using Rhodamine G (Fluka Chemie AG, Buchs, Switzerland) and co-migration with known standards. The monoacylglycerol and phospholipid spots were incompletely separated and were examined as one fraction, referred to as the phospholipid fraction. Heneicosanoic acid (21:0) was added to the extracts as internal standard. The extracts were transesterified using boron fluoride-methanol (Morrison \& Smith, 1964). To remove neutral sterols and non-saponifiable material, the extracts were heated in $0.5 \mathrm{M}-\mathrm{KOH}$ in ethanol-water solution (9:1). Recovered fatty acids were re-esterified using boron fluoride-methanol. The methyl esters were quantified as previously described (Wergedahl et al. 2004).

\section{Scharlach red staining of liver}

In order to study neutral fat deposits, $10 \mu \mathrm{m}$ frozen sections from the livers were cut, stained with a filtered Scharlach red solution and visualised by light microscopy. 


\section{Lipid quantification}

Triacylglycerol in liver, plasma and triacylglycerol-rich lipoproteins were measured enzymatically using the triacylglycerol kit from Bayer (Tarrytown, NY, USA). Phospholipids in liver were measured using the phospholipid kit from bioMerieux (Lyon, France). NEFA in plasma were measured using the NEFA C kit from Wako Chemicals (Dalton, OH, USA) on the Hitachi 917 system (Roche Diagnostics GmbH, Mannheim, Germany). Liver lipids were extracted by the method of Bligh and Dyer (Bligh \& Dyer, 1959), evaporated under $\mathrm{N}$ and re-dissolved in isopropanol before analysis.

\section{Plasma transaminases}

The plasma levels of alanine transaminase and aspartate transaminase were measured on the Hitachi 917 system (Roche Diagnostics) using the appropriate kits from Roche Diagnostics.

\section{Real-time quantitative $R T-P C R$}

Total RNA was purified from frozen liver, epididymal WAT and skeletal muscle using RNeasy Midi Kit (Qiagen, Hilden, Germany). For isolation of RNA from WAT, QIAzol Lysis Reagent (Qiagen) was added to the samples and the extraction was performed with chloroform. For isolation of RNA from muscle, proteinase K (Qiagen) was added to the samples. Primers and Taqman probe for rat carnitine palmitoyltransferase (CPT)-Ia, CPT-II, $\Delta 5$ desaturase, $\Delta 6$ desaturase, glyceraldehyde-3-phosphate dehydrogenase, $\operatorname{PPAR} \alpha$, stearoyl-CoA desaturase and sterol regulatory binding protein-1c were designed using Primer Express (Applied Biosystems, Foster City, CA, USA). Gene expressions were determined using Taqman probes or SYBRgreen. The following sequences were used: CPT-Ia forward 5'-CCC AGT GGG AGC GAC TCT T- $3^{\prime}$, reverse $5^{\prime}$-TGT GCC TGC TGT CCT TGA TAT G- $3^{\prime}$ and probe $5^{\prime}$-AGG AGA CAG ACA CCA TC- $3^{\prime}$. CPTII forward 5'-ATT ATC TGC AGC ACA GCA TCG T-3', reverse $5^{\prime}$-TGC ATT GAG GTA TCT CTT CAT GGT-3' and probe $5^{\prime}$-TGC CCA GGC TGC CTA- $3^{\prime} . \Delta 5$ desaturase forward 5'-TGG ATC TTT GGA ACT TCC TTG GT-3', reverse $5^{\prime}$-CAA AGT CAT GCT GTA GCC AAC CT- $3^{\prime}$ and probe $5^{\prime}$-CAG TTC AGG CCC AGG C- $3^{\prime} . \Delta 6$ desaturase forward 5'-CAG CGG GCA CCT CAA TTT-3', reverse 5'-TGC TTG GCG CAG AGA GAC T-3' and probe $5^{\prime}$-CAG ATT GAG CAC CAC CTC TTC CCC AC-3'. Glyceraldehyde-3phosphate dehydrogenase forward 5'-TGC ACC ACC AAC TGC TTA GC- $3^{\prime}$, reverse $5^{\prime}-\mathrm{CAG}$ TCT TCT GAG TGG CAG TGA TG- $3^{\prime}$ and probe $5^{\prime}$-TGG AAG GGC TCA TGA CCA CAG TCC A-3'. PPAR $\alpha$ forward 5'-TGG AGT CCA CGC ATG TGA AG- $3^{\prime}$, reverse $5^{\prime}-\mathrm{CAG}$ TCT TCT GAG TGG CAG TGA TG- $3^{\prime}$ and probe $5^{\prime}$-TGG AAG GGC TCA TGA CCA CAG TCC A-3'. Stearoyl-CoA desaturase-1 forward $5^{\prime}$-CCT CAT CAT TGC CAA CAC CAT- $3^{\prime}$, reverse $5^{\prime}$-CGG CGT GTG TCT CAG AGA AC- $3^{\prime}$ and probe $5^{\prime}$ TCC CAG AAC GAT GTA TAT GAA TGG GCC C-3'. Sterol regulatory element binding protein-1c forward $5^{\prime}-$ GGA GCC ATG GAT TGC ACA TTT G-3', reverse 5'CAA ATA GGC CAG GGA AGT CAC-3'. apo B (Rn01499049_g1), arylacetamide deacetylase (AADA;
Rn00571934_m1), elongase (Rn00592812), fatty acid translocase (FAT/CD36; Rn00580728_m1), hormone-sensitive lipase (Rn00563444_m1), liver fatty acid-binding protein (Rn00664587_m1), lipoprotein lipase (LPL; Rn00561482_m1), PPARס (Rn00565707_m1), PPAR $\gamma$ (Rn00440945_m1) and VLDL receptor (Rn005784) are 'Assay-on Demand' designed by Applied Biosystems.

Real-time RT-PCR was carried out in triplicate on an ABI 7900 sequence detection system (Applied Biosystems). A dilution curve from one cDNA source using dilutions $1: 2$, 1:4, 1:8 and a no-template control was run for each gene. The gene expression was determined by relative quantification using the standard curve method. For each sample, results were normalised to glyceraldehyde-3-phosphate dehydrogenase mRNA and 18S rRNA (RT-CKFT-18S; MedProbe, Oslo, Norway). Only results normalised to $18 \mathrm{~S}$ rRNA are shown, as they were similar to the results normalised to glyceraldehyde-3-phosphate dehydrogenase mRNA.

\section{Preparation of hepatic subcellular fractions}

Homogenisation and subcellular fractionation of the livers were performed as previously described (Berge et al. 1984). The procedure was performed at $0-4^{\circ} \mathrm{C}$, and the fractions were stored at $-80^{\circ} \mathrm{C}$. Protein was assayed with the BioRad protein assay kit (BioRad, Richmond, CA, USA) using bovine serum albumin as the standard.

\section{Enzyme assays}

Palmitoyl-CoA and palmitoyl-L-carnitine oxidation were measured in the mitochondrial fraction as acid-soluble products (Willumsen et al. 1993). CPT-I and CPT-II activities were measured in the mitochondrial fraction (Madsen et al. 1998). Fatty acyl-CoA oxidase was measured in the peroxisomal fraction (Small et al. 1985). 3-Hydroxy-3-methylglutarylCoA synthase was measured spectrophotometrically in the mitochondrial fraction (Clinkenbeard et al. 1975). AcetylCoA carboxylase activity was measured in cytosolic fraction by measuring the amount of $\mathrm{NaH}^{14} \mathrm{CO}_{3}$ incorporated into malonyl-CoA (Tanabe et al. 1981). Fatty acid synthase activity was measured in the cytosolic fraction as described by Roncari (1981), modified according to Skorve et al. (1993). Glycerol3-phosphate acyl transferase activity was measured in mitochondrial and microsomal fractions as described by Bates \& Saggerson (1977). Acyl-CoA synthetase activity was measured in the mitochondrial fraction (Gudbrandsen et al. 2005).

\section{Malonyl-CoA}

Malonyl-CoA in the liver was measured by reversed-phase HPLC (Wergedahl et al. 2004).

\section{Isolation of triacylglycerol-rich lipoproteins}

Plasma from two rats was pooled to obtain a volume of $3 \mathrm{ml}$. The plasma triacylglycerol-rich lipoprotein fraction was prepared as previously described (Muna et al. 2002). 


\section{Statistical analysis}

All data in the tables are presented as means and standard deviations for six rats per group. The data were evaluated by one-way ANOVA and Dunnett's test (Experiment 1, when three feeding groups were included) or by unpaired Student's $t$ test (Experiment 1, when two feeding groups were included, and Experiment 2) with the level of statistical significance set at $P<0.05$ (GraphPad Prism, version 3.0; GraphPad Prism, San Diego, CA, USA). Rats fed casein-based diet served as controls.

\section{Results}

\section{Hepatic lipids and fatty acid composition}

Scharlach red staining of the livers demonstrated that the levels of neutral lipids were decreased by HDI feeding, as the lipid droplets were both fewer and smaller (Fig. 1). Quantification of the hepatic triacylglycerol level showed that HDI reduced the level of triacylglycerol by $67 \%$ (Table 2). The reduced fatty liver by HDI was accompanied with reduced plasma levels of alanine transaminase and aspartate transaminase by more than $80 \%$ (Table 2). The hepatic phospholipid level was not changed after HDI feeding (Table 2). When rats were fed LDI, no effects were seen in the liver lipid content or in the plasma transaminases (Fig. 1; Table 2).

HDI feeding changed the fatty acid composition of the hepatic lipids (Table 3). The level of 16:0 was decreased in triacylglycerol, phospholipids and 1,2-diacylglycerol, whereas the level of 18:0 was increased in phospholipids and 1,2diacylglycerol after HDI feeding (Table 2). This resulted in an increased 18:0/16:0 ratio in phospholipids, triacylglycerol and 1,2-diacylglycerol (calculated from Table 3), concomitant with an increased mRNA level of elongase in liver of HDI-fed rats (Table 4).

The levels of the $\Delta 9$ desaturated fatty acids $16: 1 n-7$ and $18: 1 n-9$ in liver lipids were not changed by HDI feeding, except for a decreased level of 18:1n-9 in 1,2-diacylglycerol (Table 3). The mRNA level of stearoyl-CoA desaturase-1, the rate-limiting enzyme catalysing the synthesis of $\Delta 9$ desaturated MUFA, was not significantly changed by HDI (Table 4 ).

The phospholipid levels of $18: 2 n-6,18: 3 n-6,20: 3 n-6$, $18: 3 n-3$ and $20: 5 n-3$ were increased and the level of $20: 4 n-6$ was decreased after HDI feeding. In addition, HDIfed rats had an increased level of $20: 3 n-6$ in triacylglycerol and 1,2-diacylglycerol and of 20:4n-6 acid in triacylglycerol, 1,2-diacylglycerol and as NEFA. HDI feeding also increased the level of $20: 5 n-3$ in 1,2-diacylglycerol, and that of $22: 5 n-3$ and $22: 6 n-3$ in triacylglycerol (Table 3 ). The ratio of $n-3$ to $n-6$ was increased in triacylglycerol and decreased in 1,2-diacylglycerol by HDI feeding (Table 5). HDI feeding decreased the $20: 4 n-6 / 18: 2 n-6$ and the $(20: 5 n-3+22: 6 n$ $3) / 18: 3 n-3$ ratios in phospholipids, whereas these ratios were increased in triacylglycerol (Table 5). The $\Delta 6$ and $\Delta 5$ desaturases catalyse the biosynthesis of long-chain $n-6$ and $n$-3 PUFA from the precursors $18: 2 n-6$ and $18: 3 n-3$, respectively. The mRNA level of $\Delta 6$ desaturase was not affected, but the mRNA level of $\Delta 5$ desaturase was significantly decreased by HDI feeding (Table 4).

The fatty acid composition of phospholipids, triacylglycerol, 1,2-diacylglycerol and NEFA and the mRNA levels of elongase and desaturases in liver were not affected by LDI feeding (data not shown).

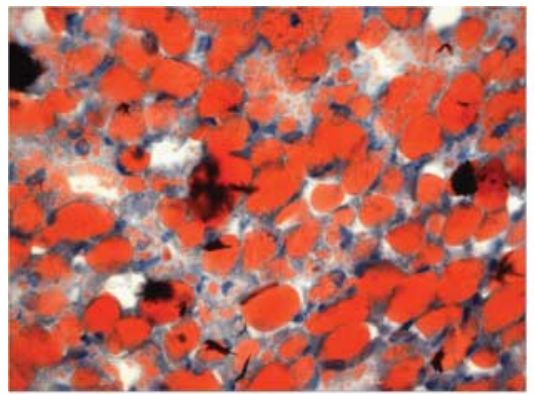

Casein

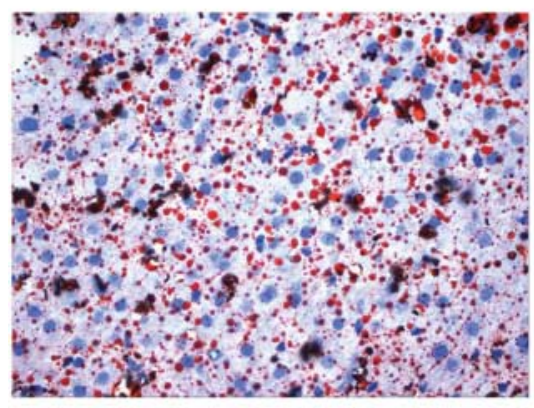

HDI

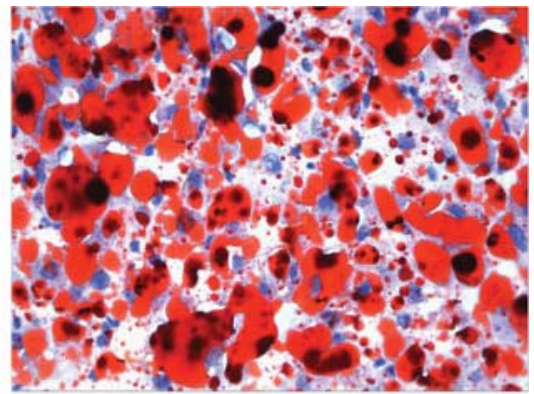

LDI

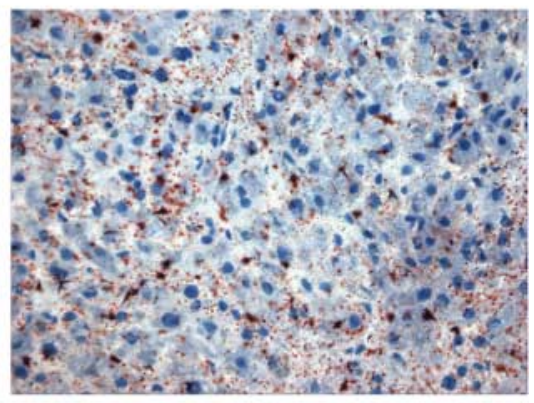

Soya protein

Fig. 1. Fat-stained microphotographs from livers of Zucker rats fed a diet containing casein, a low dose of soya protein concentrate enriched with isoflavones (LDI), a high dose of soya protein concentrate enriched with isoflavones (HDI) or soya protein, showing one representative example from each feeding group. For details of procedures, see p. 250. Scharlach red, original magnifications $\times 50$. 
Table 2. Hepatic lipids and plasma transaminases in obese Zucker rats fed a diet containing casein, a low dose of soya protein concentrate enriched with isoflavones (LDI) or a high dose of soya protein concentrate enriched with isoflavones (HDI) $†$

(Mean values and standard deviations for six rats per group)

\begin{tabular}{|c|c|c|c|c|c|c|}
\hline & \multicolumn{2}{|c|}{ Casein } & \multicolumn{2}{|c|}{ LDI } & \multicolumn{2}{|c|}{ HDI } \\
\hline & Mean & SD & Mean & SD & Mean & SD \\
\hline \multicolumn{7}{|l|}{ Hepatic lipids ( $\mu \mathrm{mol} / \mathrm{g}$ liver) } \\
\hline Triacylglycerol & 404 & 59 & 373 & 59 & $135^{\star}$ & 20 \\
\hline Phospholipids & 45 & 5 & 44 & 5 & 43 & 5 \\
\hline \multicolumn{7}{|l|}{ Plasma transaminases (U/I) } \\
\hline Alanine transaminase & 465 & 155 & 417 & 269 & $83^{*}$ & 24 \\
\hline Aspartate transaminase & 973 & 270 & 569 & 235 & $128^{*}$ & 31 \\
\hline
\end{tabular}

Mean values were significantly different from those of the control (casein) group: ${ }^{*} P<0.05$

†For details of diets and procedures, see Table 1 and p. 250.

\section{Hepatic lipid metabolism}

The activation of fatty acids in mitochondria was increased, as the activity of mitochondrial acyl-CoA synthetase was increased by $69 \%$ after HDI feeding (Table 6). HDI feeding increased the mitochondrial $\beta$-oxidation, measured as acidsoluble products after oxidation of palmitoyl-CoA and palmitoyl-L-carnitine by 59 and $110 \%$, respectively (Table 6). This was accompanied by a $55 \%$ increase in the CPT-II activity, whereas the CPT-I activity was similar to that of controls (Table 6). However, the gene expressions of CPT-I and CPT-II were not affected by HDI feeding (Table 4). The malonyl-CoA level and the malonyl-CoA sensitivity of CPT-I in liver of rats fed HDI were similar to controls (data not shown). The peroxisomal $\beta$-oxidation, measured as acylCoA oxidase activity in peroxisomes, was increased by $52 \%$ after HDI feeding (Table 6). The gene expressions of PPAR $\alpha$ and PPAR $\delta$ in liver were decreased by 47 and $36 \%$ after HDI feeding, respectively, whereas the mRNA level of liver fatty acid-binding protein was unchanged (Table 4). The activity of mitochondrial 3-hydroxy-3-methylglutarylCoA synthase, the rate-limiting enzyme in ketogenesis, was not affected by HDI feeding (Table 6).

HDI feeding affected the biosynthesis of both fatty acids and glycerolipids, as the cytosolic activities of acetyl-CoA carboxylase and fatty acid synthase as well as mitochondrial and microsomal glycerol-3-phosphate acyltransferase were increased by $86,170,175$ and $52 \%$, respectively (Table 6). In addition, the gene expression of sterol regulatory element binding protein-1c was increased by $138 \%$, whereas the mRNA level of PPAR $\gamma$ was decreased by $61 \%$ after HDI feeding (Table 4).

\section{Plasma lipids and fatty acids}

The triacylglycerol level in plasma and in triacylglycerol-rich lipoproteins increased by 602 and $146 \%$, respectively, after HDI feeding (Table 7). HDI feeding also increased the plasma level of NEFA by $121 \%$ (Table 7).

The effects of HDI feeding on the fatty acid composition in plasma were quite different from what was seen in liver (Table $3)$. In general, disparate effects were seen in the changes of $16: 0$ and $18: 1 n-9$ levels, whereas the changes in the $n-6$ and the shorter $n$ - 3 PUFA were similar in plasma and hepatic phospholipids after HDI feeding (Table 3). HDI feeding increased the levels of $16: 0,18: 1 n-9,18: 2 n-6,18: 3 n-6$, $20: 3 n-6,18: 3 n-3,20: 5 n-3$ and $22: 5 n-3$ and reduced the levels of $20: 4 n-6$ and $22: 6 n-3$ (Table 3).

\section{Secretion and clearance of lipids}

HDI feeding decreased the mRNA levels of both AADA and apo B (Table 4). The mRNA level of hormone-sensitive lipase in epididymal WAT, and that of VLDL receptor and LPL in epididymal WAT and skeletal muscle were not changed (Table 8). HDI feeding increased the mRNA level of LDL receptor in epididymal WAT and skeletal muscle by 86 and $37 \%$, respectively (Table 8). The mRNA level of FAT/ CD36 was increased by $60 \%$ in epididymal WAT (Table 8), but was not changed in liver (Table 4) or in skeletal muscle (Table 8). The gene expressions of VLDL receptor and LPL in liver were down-regulated by 74 and $93 \%$, respectively, in rats fed HDI (Table 4).

\section{Soya protein experiment}

When obese Zucker rats were fed intact soya protein, a distinct decrease was seen in the size and number of fat droplets in liver as compared with casein-fed rats (Fig. 1). Soya protein feeding had no effect on the gene expressions of apo B and AADA, but down-regulated the mRNA levels of VLDL receptor and LPL in liver by almost $70 \%$ (Table 9).

\section{Discussion}

When obese Zucker rats were fed a diet containing casein with a high amount of an isoflavone-enriched soya concentrate added (HDI), fewer and smaller fat droplets in liver resulted when compared with control rats fed casein. Quantitative measurements showed that the level of triacylglycerol in the liver was reduced accordingly. The reduced plasma levels of transaminases further supported that HDI feeding reduced fatty liver in this animal model.

The reduced fatty liver by HDI could be caused by increased $\beta$-oxidation, decreased lipid biosynthesis, increased secretion of VLDL and/or decreased clearance from plasma. The increased $\beta$-oxidation after HDI feeding reduced the availability of fatty acids for biosynthesis and secretion of triacylglycerol as VLDL. However, the increased lipogenesis and glycerolipid biosynthesis suggested that increased amounts of triacylglycerols and phospholipids were available for VLDL secretion. The decreased mRNA levels of AADA, a lipase involved in the mobilisation of triacylglycerol from hepatocytes to the VLDL particle (Trickett et al. 2001), and of apo B, provided strong indices of a reduced secretion of VLDL from the liver of HDI-fed rats. Thus, these data argue against an increased hepatic secretion of VLDL particles as the cause for the reduced fatty liver in HDI-fed rats.

The markedly down-regulated gene expression of the VLDL receptor and of LPL in liver by HDI may explain both the reduced fatty liver and the increased contents of triacylglycerol and NEFA in plasma. Normally, VLDL receptor and LPL are mainly expressed in adipose tissue and muscle, and only at very low levels in liver (Oka et al. 1994). As 
O. A. Gudbrandsen et al.

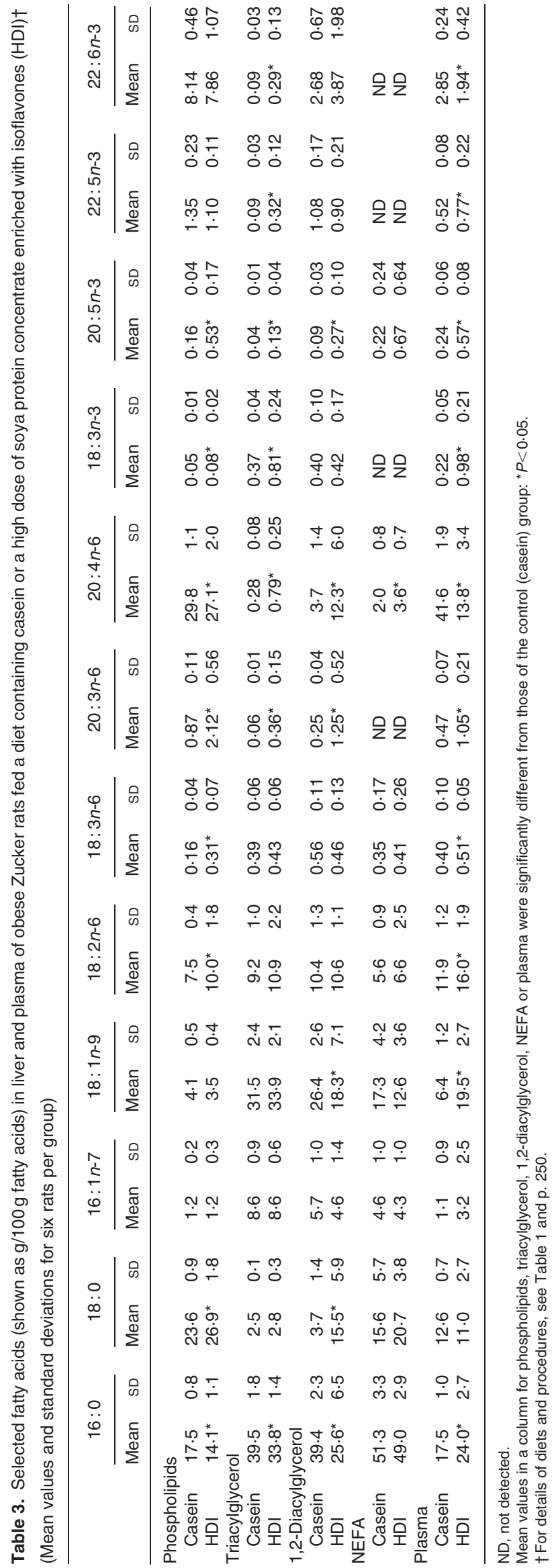


Table 4. Hepatic mRNA levels in obese Zucker rats fed a diet containing casein or a high dose of soya protein concentrate enriched with isoflavones (HDI), presented relative to 18S rRNA and normalised to controls $†$

(Mean values and standard deviations for six rats per group)

\begin{tabular}{|c|c|c|c|c|}
\hline & \multicolumn{2}{|c|}{ Casein } & \multicolumn{2}{|c|}{$\mathrm{HDI}$} \\
\hline & Mean & SD & Mean & SD \\
\hline AADA & 1.00 & 0.08 & $0.75^{*}$ & 0.15 \\
\hline Apo B & 1.00 & 0.12 & $0.71^{*}$ & 0.26 \\
\hline CPT-la & 1.00 & 0.37 & 1.01 & 0.25 \\
\hline CPT-II & 1.00 & 0.31 & $1 \cdot 12$ & 0.13 \\
\hline$\Delta 5$ desaturase & 1.00 & 0.21 & $0.65^{*}$ & 0.21 \\
\hline$\Delta 6$ desaturase & 1.00 & 0.19 & 0.96 & 0.28 \\
\hline Elongase & 1.00 & 0.11 & $1 \cdot 24^{*}$ & 0.13 \\
\hline FAT/CD36 & 1.00 & 0.27 & $1 \cdot 11$ & 0.25 \\
\hline L-FABP & 1.00 & 0.24 & $1 \cdot 11$ & 0.25 \\
\hline LPL & 1.00 & 0.39 & $0.07^{*}$ & 0.01 \\
\hline $\operatorname{PPAR} \alpha$ & 1.00 & 0.14 & $0.53^{*}$ & 0.19 \\
\hline PPAR $\delta$ & 1.00 & 0.20 & $0.64^{*}$ & 0.26 \\
\hline PPAR $\gamma$ & 1.00 & 0.40 & $0.39^{*}$ & 0.27 \\
\hline SCD-1 & 1.00 & 0.25 & 1.23 & 0.29 \\
\hline SREBP-1C & 1.00 & 0.15 & $2 \cdot 38^{*}$ & 0.72 \\
\hline VLDL receptor & 1.00 & 0.37 & $0.26^{*}$ & 0.04 \\
\hline
\end{tabular}

AADA, arylacetamide deacetylase; CPT, carnitine palmitoyltransferase; FAT/CD36 fatty acid translocase; L-FABP, liver fatty acid-binding protein; LPL, lipoprotein lipase; SCD-1, stearoyl-CoA desaturase; SREBP, sterol regulatory binding protein.

Mean values were significantly different from those of the control (casein) group: ${ }^{*} P<0.05$.

†For details of diets and procedures, see Table 1 and p. 250.

HDI did not affect the mRNA levels of these genes in epididymal WAT or skeletal muscle, the liver appears to be the key organ for the reduced clearance of VLDL from plasma. Furthermore, the unchanged gene expression of LPL in epididymal WAT and skeletal muscle suggested that HDI feeding did not affect the uptake of lipids to these tissues.

Table 5. Ratios of fatty acids in hepatic lipids from obese Zucker rats fed a diet containing casein or a high dose of soya protein concentrate enriched with isoflavones (HDI) $\dagger$

(Mean values and standard deviations for six rats per group)

\begin{tabular}{|c|c|c|c|c|}
\hline & \multicolumn{2}{|c|}{ Casein } & \multicolumn{2}{|c|}{ HDI } \\
\hline & Mean & SD & Mean & SD \\
\hline \multicolumn{5}{|l|}{$n-3 / n-6$} \\
\hline Phospholipids & 0.24 & 0.01 & 0.23 & 0.03 \\
\hline Triacylglycerol & 0.06 & 0.01 & $0 \cdot 12^{*}$ & 0.02 \\
\hline 1,2-Diacylglycerol & 0.27 & 0.02 & $0 \cdot 20^{\star}$ & 0.03 \\
\hline NEFA & 0.03 & 0.03 & 0.06 & 0.03 \\
\hline \multicolumn{5}{|l|}{$20: 4 n-6 / 18: 2 n-6$} \\
\hline Phospholipids & 4.00 & 0.34 & $2 \cdot 82^{*}$ & 0.69 \\
\hline Triacylglycerol & 0.03 & 0.01 & $0.07^{\star}$ & 0.02 \\
\hline 1,2-Diacylglycerol & 0.35 & $0 \cdot 12$ & $1 \cdot 17^{*}$ & 0.56 \\
\hline NEFA & 0.35 & 0.11 & $0.56^{*}$ & 0.10 \\
\hline \multicolumn{5}{|c|}{$(20: 5 n-3+22: 6 n-3) / 18: 3 n-3$} \\
\hline Phospholipids & 190 & 39 & $106^{*}$ & 27 \\
\hline Triacylglycerol & 0.34 & 0.09 & $0.52^{*}$ & 0.09 \\
\hline 1,2-Diacylglycerol & $7 \cdot 0$ & 1.5 & $11 \cdot 7$ & $7 \cdot 2$ \\
\hline NEFA‡ & - & - & - & - \\
\hline
\end{tabular}

Mean values were significantly different from those of the control (casein) group: ${ }^{*} P<0.05$.

†For details of diets and procedures, see Table 1 and p. 250.

$\ddagger 18: 3 n-3$ and $22: 6 n-3$ were not found in NEFA.
Table 6. Activities of enzymes ( $\mathrm{nmol} / \mathrm{mg}$ protein per min) involved in fatty acid oxidation and in biosynthesis of fatty acids and lipids in liver of obese Zucker rats fed a diet containing casein or a high dose of soya protein concentrate enriched with isoflavones (HDI)†

(Mean values and standard deviations for six rats per group)

\begin{tabular}{|c|c|c|c|c|}
\hline & \multicolumn{2}{|c|}{ Casein } & \multicolumn{2}{|c|}{ HDI } \\
\hline & Mean & SD & Mean & SD \\
\hline Acyl-CoA synthetase $\ddagger$ & $36 \cdot 9$ & $3 \cdot 8$ & $62 \cdot 3^{*}$ & 7.9 \\
\hline \multicolumn{5}{|l|}{$\beta$-Oxidation $\ddagger$} \\
\hline Palmitoyl-CoA & 0.54 & 0.12 & $0.86^{*}$ & 0.05 \\
\hline Palmitoyl-L-carnitine & 0.58 & 0.12 & $1 \cdot 22^{*}$ & 0.30 \\
\hline CPT-I† & $2 \cdot 9$ & 0.3 & $3 \cdot 2$ & 0.3 \\
\hline CPT-II & $13 \cdot 6$ & $2 \cdot 4$ & $21 \cdot 2^{*}$ & $2 \cdot 4$ \\
\hline Acyl-CoA oxidase§ & $18 \cdot 0$ & $1 \cdot 8$ & $27 \cdot 4^{*}$ & $3 \cdot 1$ \\
\hline HMG-CoA synthase & $15 \cdot 6$ & $2 \cdot 8$ & $14 \cdot 0$ & $1 \cdot 6$ \\
\hline Acetyl-CoA carboxylase & $9 \cdot 4$ & $1 \cdot 3$ & $17 \cdot 5^{\star}$ & $1 \cdot 8$ \\
\hline Fatty acid synthetase $\|$ & 0.43 & 0.05 & $1 \cdot 16^{*}$ & 0.27 \\
\hline GPAT & $1 \cdot 2$ & 0.2 & $3 \cdot 3^{*}$ & 1.6 \\
\hline GPATq & $2 \cdot 1$ & 0.5 & $3 \cdot 2^{*}$ & 0.9 \\
\hline
\end{tabular}

CPT, carnitine palmitoyltransferase; GPAT, glycerol-3-phosphate acyltransferase; HMG, 3-hydroxy-3-methylglutaryl.

Mean values were significantly different from those of the control (casein) group: ${ }^{*} P<0.05$.

†For details of diets and procedures, see Table 1 and p. 250.

$\ddagger$ Enzyme activities were measured in mitochondria.

$\S$ Enzyme activities were measured in peroxisomes.

\| Enzyme activities were measured in cytosol.

I Enzyme activities were measured in microsomes.

HDI feeding increased the mRNA level of the LDL receptor in liver (Gudbrandsen et al. 2005), epididymal WAT and skeletal muscle. There is substantial evidence that the LDL receptor contributes to the clearance of not only LDL, but also of VLDL (Brown \& Goldstein, 1986). However, since HDI feeding increased the triacylglycerol level both in plasma and triacylglycerol-rich lipoproteins, the LDL receptor appears to contribute little to the uptake of VLDL in these rats.

The increased plasma level of NEFA after HDI feeding was probably not due to an increased release from epididymal WAT to plasma, as the mRNA level of hormone-sensitive lipase in epididymal WAT was unchanged. The uptake of NEFA to liver, epididymal WAT and skeletal muscle via FAT/CD36 was probably not decreased, as the mRNA level of FAT/CD36 in these tissues was either unchanged or increased, and could not explain the increased plasma level of NEFA by the HDI diet.

Although the gene expression of $\Delta 6$ desaturase was not affected by HDI feeding, the reduced mRNA level of $\Delta 5$ desaturase implied that the biosynthesis of $20: 4 n-6$ from $18: 2 n-6$ and that of $20: 5 n-3$ from $18: 3 n-3$ in liver was impaired, and this was supported by the decreased product/precursor ratios of the $n-6$ and $n-3$ cascades in phospholipids. The triacylglycerols comprise most of the liver lipids in obese Zucker rats and, interestingly, HDI feeding increased the $n-3 / n-6$, the $20: 4 n-6 /$ $18: 2 n-6$ and the $(20: 5 n-3+20: 6 n-3) / 18: 3 n-3$ ratios in liver triacylglycerols. This is an important finding since it has been shown that these ratios are decreased in patients with fatty liver (Videla et al. 2004). The increased product/precursor ratio and increased $n-3 / n-6$ may favour $\beta$-oxidation over the synthesis of fatty acids and triacylglycerol, as long-chain PUFA, especially the $n-3$ PUFA, are activators of PPAR $\alpha$ (Clarke, 2001), and thus suggest that HDI may be useful to prevent or treat fatty liver in man. Although genistein and daidzein have 
Table 7. Plasma levels of triacylglycerol and NEFA, and triacylglycerol in triacylglycerol-rich lipoproteins in obese Zucker rats fed a diet containing casein or a high dose of soya protein concentrate enriched with isoflavones (HDI)†

(Mean values and standard deviations for six rats per group (in plasma) or three pooled samples of two rats each (triacylglycerol-rich lipoproteins))

\begin{tabular}{llllll}
\hline & \multicolumn{2}{c}{ Casein } & & \multicolumn{2}{c}{ HDI } \\
\cline { 2 - 3 } & Mean & SD & & Mean & SD \\
\hline Plasma levels (mM) & & & & \\
$\quad$ Triacylglycerol & 0.83 & 0.14 & & $5.83^{*}$ & 0.93 \\
$\quad$ NEFA & 0.97 & 0.26 & & $2.39^{*}$ & 0.40 \\
Triacylglycerol-rich lipoproteins (mol/mg protein) & & & \\
$\quad$ Triacylglycerol & 12.8 & 3.4 & & $28.3^{*}$ & \\
\hline
\end{tabular}

Mean values were significantly different from those of the control (casein) group: ${ }^{*} P<0.05$.

†For details of diets and procedures, see Table 1 and p. 250

been reported to activate PPAR $\alpha$ in vitro (Mezei et al. 2003), we found a decreased gene expression of not only PPAR $\alpha$, but also of PPAR $\delta$ and PPAR $\gamma$, after HDI feeding.

The reduced content of $20: 4 n-6$ and the increased content of $20: 5 n-3$ in phospholipids after HDI feeding imply that this diet may prevent the development of atherosclerosis and other inflammatory diseases, as this may favour the production of anti-inflammatory over pro-inflammatory eicosanoids.

The changes in fatty acid composition in plasma after HDI feeding was not similar to what was seen in any lipid fraction isolated from liver. Since triacylglycerol-rich lipoproteins from obese Zucker rats fed casein contain approximately $80 \%$ triacylglycerol (OA Gudbrandsen, $\mathrm{H}$ Wergedahl and RK Berge, unpublished results), the triacylglycerols will contribute to a majority of the fatty acids in plasma. Certain analogous changes were seen in plasma and liver phospholipids, especially regarding the $n-6$ and $n$-3 PUFA, possibly because a sizeable portion of VLDL triacylglycerol arise from cellular fatty

Table 8. mRNA levels in epididymal white adipose tissue (WAT) and skeletal muscle of obese Zucker rats fed a diet containing casein or a high dose of soya protein concentrate enriched with isoflavones (HDI), presented relative to $18 \mathrm{~S}$ rRNA and normalised to controls $†$

(Mean values and standard deviations for six rats per group)

\begin{tabular}{llllll}
\hline & \multicolumn{2}{c}{ Casein } & & \multicolumn{2}{c}{ HDI } \\
\cline { 2 - 3 } \cline { 5 - 6 } & Mean & SD & & Mean & SD \\
\hline Epididymal WAT & & & & \\
FAT/CD36 & 1.00 & 0.24 & & $1.60^{*}$ & 0.14 \\
HSL & 1.00 & 0.23 & & 0.86 & 0.24 \\
LPL & 1.00 & 0.17 & 1.01 & 0.12 \\
LDL receptor & 1.00 & 0.13 & $1.86^{*}$ & 0.47 \\
VLDL receptor & 1.00 & 0.11 & & 0.99 & 0.12 \\
Skeletal muscle & & & & \\
FAT/CD36 & 1.00 & 0.10 & & 1.18 & 0.27 \\
LPL & 1.00 & 0.19 & & 0.94 & 0.16 \\
VLDL receptor & 1.00 & 0.10 & & 0.90 & 0.09 \\
LDL receptor & 1.00 & 0.22 & $1.37^{*}$ & 0.25 \\
\hline
\end{tabular}

FAT/CD36, fatty acid translocase; HSL, hormone-sensitive lipase; LPL, lipoprotein lipase.

Mean values were significantly different from those of the control (casein) group: ${ }^{*} P<0.05$.

†For details of diets and procedures, see Table 1 and p. 250
Table 9. mRNA levels in liver of obese Zucker rats fed a diet containing casein or soya protein, presented relative to $18 \mathrm{~S}$ rRNA and normalised to controls $†$

(Mean values and standard deviations for six rats per group)

\begin{tabular}{lcclll}
\hline & \multicolumn{2}{c}{ Casein } & & \multicolumn{2}{c}{ Soya protein } \\
\cline { 2 - 3 } & Mean & SD & & Mean & SD \\
\hline AADA & 1.00 & 0.11 & & 0.96 & 0.11 \\
Apo B & 1.00 & 0.10 & & 0.91 & 0.07 \\
LPL & 1.00 & 0.25 & & $0.31^{*}$ & 0.08 \\
VLDL receptor & 1.00 & 0.43 & & $0.32^{*}$ & 0.16 \\
\hline
\end{tabular}

AADA, arylacetamide deacetylase; LPL, lipoprotein lipase.

Mean values were significantly different from those of the control (casein) group: ${ }^{*} P<0.05$.

†For details of diets and procedures, see Table 1 and p. 250

acids esterified as phospholipids (Wiggins \& Gibbons, 1996). The markedly increased $18: 1 n-9$ and decreased $20: 4 n-6$ levels in plasma after HDI feeding were not seen in any liver lipids except for cholesteryl esters (Gudbrandsen et al. 2005), supporting findings showing that cholesteryl esters of VLDL are non-selectively transferred from the liver (Gidez et al. 1965).

We have previously demonstrated that dietary soya protein lowers the hepatic lipid content in obese Zucker rats (Wergedahl et al. 2004). In the present study we show that the mechanism of action of the soya protein is similar to that of HDI, as soya protein appears to enhance $\beta$-oxidation (Wergedahl et al. 2004) and probably does not increase the secretion of VLDL from liver, as the mRNA levels of AADA and apo B were not changed. In addition, soya protein feeding decreased the mRNA levels of VLDL receptor and LPL, indicating that also with intact soya protein the reduced fatty liver might be due to decreased clearance of VLDL from plasma. Since the amino acid compositions of casein and HDI diets were almost similar (Gudbrandsen et al. 2005), while that of soya protein was markedly different (Wergedahl et al. 2004), this suggests that the isoflavones and not the amino acids may be the bioactive components of the HDI diet.

To conclude, the reduced fatty liver in obese Zucker rats fed HDI or soya protein appear to be due to increased catabolism of fatty acids in liver combined with reduced clearance of VLDL from the circulation by the liver.

\section{Acknowledgements}

Åse Helltveit, Svein Kryger, Kari Helland Mortensen, Bjørn Netteland, Karen Bøhm Nilssen, Randi Sandvik, Randi Solheim, Sissel Marie Torheim, Laila Vaardal, Jacob Wessels, Kari Williams and Liv Kristine Øysæd are acknowledged for their technical assistance. This research was supported by the Norwegian Cancer Society and the Norwegian Research Council.

\section{References}

Ali AA, Velasquez MT, Hansen CT, Mohamed AI \& Bhathena SJ (2004) Effects of soybean isoflavones, probiotics, and their interactions on lipid metabolism and endocrine system in an animal model of obesity and diabetes. J Nutr Biochem 15, 583-590.

Anderson JW, Johnstone BM \& Cook-Newell ME (1995) Meta-analysis of the effects of soy protein intake on serum lipids. $N$ Engl $J$ Med 333, 276-282. 
Angulo P \& Lindor KD (2002) Non-alcoholic fatty liver disease. J Gastroenterol Hepatol 17, S186-S190.

Balmir F, Staack R, Jeffrey E, Jimenez MD, Wang L \& Potter SM (1996) An extract of soy flour influences serum cholesterol and thyroid hormones in rats and hamsters. J Nutr 126, 3046-3053.

Bates EJ \& Saggerson D (1977) A selective decrease in mitochondrial glycerol phosphate acyltransferase activity in livers from streptozotocin-diabetic rats. FEBS Lett 84, 229-232.

Berge RK, Flatmark T \& Osmundsen H (1984) Enhancement of longchain acyl-CoA hydrolase activity in peroxisomes and mitochondria of rat liver by peroxisomal proliferators. Eur J Biochem 141, 637-644.

Bligh EG \& Dyer WJ (1959) A rapid method of total lipid extraction and purification. Can J Biochem Physiol 37, 911-917.

Bray GA (1977) The Zucker-fatty rat: a review. Fed Proc 36, 148-153.

Brown MS \& Goldstein JL (1986) A receptor-mediated pathway for cholesterol homeostasis. Science 232, 34-47.

Clarke SD (2001) Polyunsaturated fatty acid regulation of gene transcription: a molecular mechanism to improve the metabolic syndrome. J Nutr 131, 1129-1132.

Clinkenbeard KD, Reed WD, Mooney RA \& Lane MD (1975) Intracellular localization of the 3-hydroxy-3-methylglutaryl coenzyme A cycle enzymes in liver. Separate cytoplasmic and mitochondrial 3-hydroxy-3-methylglutaryl coenzyme A generating systems for cholesterogenesis and ketogenesis. J Biol Chem 250, 3108-3116.

Cohen P \& Friedman JM (2004) Leptin and the control of metabolism: role for stearoyl-CoA desaturase-1 (SCD-1). J Nutr 134, 2455S-2463S

Fukui K, Tachibana N, Wanezaki S, Tsuzaki S, Takamatsu K, Yamamoto T, Hashimoto Y \& Shimoda T (2002) Isoflavone-free soy protein prepared by column chromatography reduces plasma cholesterol in rats. J Agric Food Chem 50, 5717-5721.

Gidez LI, Roheim PS \& Eder HA (1965) Effect of diet on the cholesterol ester composition of liver and of plasma lipoproteins in the rat. J Lipid Res 6, 377-382.

Gudbrandsen OA, Wergedahl H, Liaset B, Espe M \& Berge RK (2005) Dietary proteins with high isoflavone content or low methionine-glycine and lysine-arginine ratios are hypocholesterolaemic and lower the plasma homocysteine level in male Zucker fa/fa rats. Br J Nutr 94, 321-330.

Huff MW, Hamilton RM \& Carroll KK (1977) Plasma cholesterol levels in rabbits fed low fat, cholesterol-free, semipurified diets: effects of dietary proteins, protein hydrolysates and amino acid mixtures. Atherosclerosis 28, 187-195.

Krief S \& Bazin R (1991) Genetic obesity: is the defect in the sympathetic nervous system? A review through developmental studies in the preobese Zucker rat. Proc Soc Exp Biol Med 198, $528-538$

Kritchevsky D, Tepper SA, Czarnecki SK \& Klurfeld DM (1982) Atherogenicity of animal and vegetable protein. Influence of the lysine to arginine ratio. Atherosclerosis 41, 429-431.

McClain CJ, Mokshagundam SP, Barve SS, Song Z, Hill DB, Chen T \& Deaciuc I (2004) Mechanisms of non-alcoholic steatohepatitis. Alcohol 34, 67-79.

Madani S, Lopez S, Blond JP, Prost J \& Belleville J (1998) Highly purified soybean protein is not hypocholesterolemic in rats but stimulates cholesterol synthesis and excretion and reduces polyunsaturated fatty acid biosynthesis. J Nutr 128, 1084-1091.

Madsen L, Froyland L, Dyroy E, Helland K \& Berge RK (1998) Docosahexaenoic and eicosapentaenoic acids are differently metabolized in rat liver during mitochondria and peroxisome proliferation. J Lipid Res 39, 583-593.

Mangold HK (1969) Aliphatic lipids in thin-layer chromatography. In A Laboratory Handbook, 2nd ed., pp. 363-421 [E Stahl, editor]. Berlin: Springer.

Mezei O, Banz WJ, Steger RW, Peluso MR, Winters TA \& Shay N (2003) Soy isoflavones exert antidiabetic and hypolipidemic effects through the PPAR pathways in obese Zucker rats and murine RAW 264.7 cells. J Nutr 133, 1238-1243.

Morita T, Oh-hashi A, Takei K, Ikai M, Kasaoka S \& Kiriyama S (1997) Cholesterol-lowering effects of soybean, potato and rice proteins depend on their low methionine contents in rats fed a cholesterol-free purified diet. J Nutr 127, 470-477.

Morrison WR \& Smith LM (1964) Preparation of fatty acid methyl esters and dimethylacetals from lipids with boron fluoride-methanol. J Lipid Res 5, 600-608.

Muna ZA, Gudbrandsen OA, Wergedahl H, Bohov P, Skorve J \& Berge RK (2002) Inhibition of rat lipoprotein oxidation after tetradecylthioacetic acid feeding. Biochem Pharmacol 63, $1127-1135$.

Oka K, Ishimura-Oka K, Chu MJ, Sullivan M, Krushkal J, Li WH \& Chan L (1994) Mouse very-low-density-lipoprotein receptor (VLDLR) cDNA cloning, tissue-specific expression and evolutionary relationship with the low-density-lipoprotein receptor. Eur $J$ Biochem 224, 975-982.

Peluso MR, Winters TA, Shanahan MF \& Banz WJ (2000) A cooperative interaction between soy protein and its isoflavone-enriched fraction lowers hepatic lipids in male obese Zucker rats and reduces blood platelet sensitivity in male Sprague-Dawley rats. J Nutr 130, 2333-2342.

Potter SM (1995) Overview of proposed mechanisms for the hypocholesterolemic effect of soy. J Nutr 125, 606S-611S.

Roncari DA (1981) Fatty acid synthase from human liver. Methods Enzymol 71, Pt C, 73-79.

Silverman JF, O’Brien KF, Long S, Leggett N, Khazanie PG, Pories WJ, Norris HT \& Caro JF (1990) Liver pathology in morbidly obese patients with and without diabetes. Am J Gastroenterol 85, $1349-1355$.

Sirtori CR, Even R \& Lovati MR (1993) Soybean protein diet and plasma cholesterol: from therapy to molecular mechanisms. Ann N Y Acad Sci 676, 188-201.

Skorve J, al-Shurbaji A, Asiedu D, Bjorkhem I, Berglund L \& Berge RK (1993) On the mechanism of the hypolipidemic effect of sulfur-substituted hexadecanedioic acid (3-thiadicarboxylic acid) in normolipidemic rats. J Lipid Res 34, 1177-1185.

Small GM, Burdett K \& Connock MJ (1985) A sensitive spectrophotometric assay for peroxisomal acyl-CoA oxidase. Biochem $J$ 227, $205-210$.

Tanabe T, Nakanishi S, Hashimoto T, Ogiwara H, Nikawa J \& Numa S (1981) Acetyl-CoA carboxylase from rat liver. Methods Enzymol 71, Pt C, 5-16.

Trickett JI, Patel DD, Knight BL, Saggerson ED, Gibbons GF \& Pease RJ (2001) Characterization of the rodent genes for arylacetamide deacetylase, a putative microsomal lipase, and evidence for transcriptional regulation. J Biol Chem 276, 39522-39532.

Triscari J, Greenwood MR \& Sullivan AC (1982) Oxidation and ketogenesis in hepatocytes of lean and obese Zucker rats. Metabolism 31, 223-228.

Videla LA, Rodrigo R, Araya J \& Poniachik J (2004) Oxidative stress and depletion of hepatic long-chain polyunsaturated fatty acids may contribute to nonalcoholic fatty liver disease. Free Radic Biol Med 37, 1499-1507.

Wergedahl H, Liaset B, Gudbrandsen OA, Lied E, Espe M, Muna Z, Mork S \& Berge RK (2004) Fish protein hydrolysate reduces plasma total cholesterol, increases the proportion of HDL cholesterol, and lowers acyl-CoA:cholesterol acyltransferase activity in liver of Zucker rats. J Nutr 134, 1320-1327.

Wiggins D \& Gibbons GF (1996) Origin of hepatic very-low-density lipoprotein triacylglycerol: the contribution of cellular phospholipid. Biochem J 320, Pt 2, 673-679.

Willumsen N, Hexeberg S, Skorve J, Lundquist M \& Berge RK (1993) Docosahexaenoic acid shows no triglyceride-lowering effects but increases the peroxisomal fatty acid oxidation in liver of rats. J Lipid Res 34, 13-22. 